\title{
EXPLORING THE FACTORS IN VISITORS' BEHAVIORAL INTENTIONS - MEDIATION EFFECTS ON PERCEIVED ENVIRONMENTAL INVOLVEMENT AND ECOTOURISM SUPPORT
}

\author{
DING, Z. F. ${ }^{1}-$ CAO, B. ${ }^{2 *}$ \\ ${ }^{1}$ Public Sports Department, Anshan Normal University, Anshan, Liaoning 114007, China \\ ${ }^{2}$ Physical Education Institute, Shaanxi Normal University, Xi'an, Shaanxi 710119, China \\ *Corresponding author \\ e-mail: caoben@snnu.edu.cn; phone: +86-186-2967-5612
}

(Received $18^{\text {th }}$ Sep 2018; accepted 26 $6^{\text {th }}$ Nov 2018)

\begin{abstract}
Based on resource-based theory and theory of planned behavior, this study aims to explore potential visitors' behavioral intentions to ecotourism and the interaction relations among variables of perceived environmental involvement, ecotourism support, as the mediators, and behavioral intentions, as the dependent variable. Selecting ecotourism in Sichuan Province for the research, the visitors proceeded to fill the questionnaire survey, from the potential visitors' point of view about ecotourism. A total of 348 valid copies were retrieved for the analysis of parameter estimation. They reveal positive and significant effects of visitors' innovation and interests on perceived environmental involvement, visitors' interests and perceived environmental involvement on support, as well as visitors' perceived environmental involvement and support on behavioral intentions. It is further discovered that "interests" play the key factor in driving the intention of visitors' future selection of ecotourism products. The research results provide suggestions and reference for related units in Sichuan Province developing and promoting ecotourism.
\end{abstract}

Keywords: innovation, perceived risk, perceived environmental involvement, support, behavioral intention

\section{Introduction}

Under environmental awareness, a lot of consumers have realized the direct impact of purchase behaviors on ecological problems that customers would consider environmental issues, even purchase products compatible with ecology, and are willing to pay more for environment friendly products (Laroche et al., 2001; Sahakian et al., 2018). Consumers with ecological awareness would try to protect the environment through different methods. Environmental awareness reflects on intangible service consumption, where the promotion of ecotourism or ecotourism is a significant example. Ecotourism stresses on the re-thinking of culture, education, and travel agents about recreation (Hetzer, 1965; Lee, 2014). Sichuan Province that located in the west of China is a province without sea. Coastal areas in China present better development to result in the situation of strong east and weak west. Although local authority has fully invested in the development of ecotourism, information about visitors' requirements for ecotourism is short. The understanding of potential visitors' attitudes towards and behavioral intentions of ecotourism would benefit the successive promotion of ecotourism. The strategic viewpoint of resource-based theory could be the evaluation indicator of tourist spots or the development potential of a tourist spot. Different from traditional travel patterns, ecotourism, as an emerging travel method, is the tourism activity with special interests as 
well as an innovative tourism product for visitors. It seems to induce consumers' perceived risk when purchasing ecotourism products, and such factors would possibly affect visitors' perceived environmental involvement, support, and future behavioral intentions. By reviewing past research, the lack of discussions on above variables induces the motivation of this study.

This study, based on resource-based theory and the "belief (perception) $\rightarrow$ attitude $\rightarrow$ intention" model (Oliver, 1980), aims to explore potential visitors' behavioral intentions of ecotourism products, construct visitors' innovation, perceived risk, and interests in ecotourism as the antecedents, take perceived environmental involvement and ecotourism support as the mediators, and use behavioral intentions as the dependent variable to discuss the interactive relations among such variables. Selecting Sichuan Province for the research and combining the viewpoint of potential visitors to ecotourism in Sichuan Province, the questionnaire survey is proceeded, and the research results are provided for the development and promotion of ecotourism in Sichuan Province as well as strategic reference for the promotion of ecotourism in other areas.

\section{Literature review}

\section{Effects of innovation on perceived environmental involvement and support}

There are several synonyms of "ecotourism". Such synonyms focus on "nature" and are a kind of "nature oriented tourism" mainly starting from the viewpoint of environment and developing and promoting tourism on the premise of "sustainability" (Xu et al., 2017). Overall speaking, ecotourism resources contain natural resources of scenery and wild animals and plants (Lu et al., 2017) as well as humanistic resources of local historical relics and indigenous culture (Xu et al., 2017). Those are core tourism resources for the development of ecotourism.

Innovation refers to the tendency to purchase new products more often and more rapidly than others (Midgley and Dowling, 1978; Wu et al., 2016, 2017). "Product innovation" is frequently applied to tourism and leisure industries. Ecotourism, as the tourism activity with special interests, is the tourism product aiming at consumers who are interested in special spots or activities using natural environment and space for the continuous extension (Xu et al., 2017).

Involvement is the individual inner power to affect consumer behavior in the EKB model (Engel et al., 1995). Chiu et al. (2014) pointed out involvement as invisible motivation, disturbance, or concerns induced by special situations or stimulations to affect the data collection, information processing, and decision making. Support or acceptance is an attitude. Hartini et al. (2017) regarded attitude as the psychological tendency generated through learning; such a tendency was a persistent evaluation of certain subject. Attitude strength is generally considered to be correlated with product involvement and presented with the commitment of attitude. Attitude is obedience and might achieve the level of identity. When a consumer's attitude is implanted in mind and becomes a part of the value system, the attitude might be internalized (Yoon et al., 2001; Lee and Back, 2006; Hartini et al., 2017).

This study stands for regarding consumer innovation as consumer characteristics, similar to personality traits. A visitor would be influenced the consumer behavior because of the characteristic to pursue novelty and uniqueness. Subjective curiosity plays a primary role in people's ecotourism motivation, as a visitor's subjective curiosity about ecotourism would induce the emphasis on the correlation with purchase activity. 
Referring to the belief (perception) $\rightarrow$ attitude $\rightarrow$ intention model proposed by Oliver (1980) and theory of planned behavior proposed by Ajzen and Fishbein (1980), it is inferred in this study that visitors with higher innovation would enhance the involvement in tourism products. Meanwhile, according to the psychological cognition process of belief (perception) $\rightarrow$ attitude, it is inferred that visitors with higher innovation would enhance the acceptance of tourism products. Accordingly, H1: visitors' innovation presents direct and positive effects on perceived environmental involvement and H4: visitors' innovation shows direct and positive effects on ecotourism support are proposed in this study.

\section{Effects of perceived risk on perceived environmental involvement and support}

Flynn and Goldsmith (1993) pointed out high perceived risk on purchasing new service, implying that new service marketers had to achieve consumer needs for accepting the risk. Involvement is closely related to perceived risk. According to Kapferer and Laurent (1986), consumers, when perceiving high purchase risk, would appear high concerns about the purchase behavior and higher emphasis on the correlation with oneself to present high involvement. In this case, H2: visitors' perceived risk in tourism reveals direct and positive effects on perceived environmental involvement is proposed.

$\mathrm{Xu}$ et al. (2017) found out lower intention of consumers to tourism destination with higher perceived risk in safety. According to the psychological cognition process of belief (perception) $\rightarrow$ attitude, visitors, when perceiving high purchase risk, would appear adverse effects on the acceptance of the tourism product, based on risk averse. For this reason, H5: visitors' perceived risk in tourism shows direct and negative effects on ecotourism support is proposed.

\section{Effects of interest on perceived environmental involvement and support}

"Resource-based theory" could be applied to tourism for evaluating tourist spots or the attraction and development potential of a tourist spot, providing core tourism resources for satisfying visitors' interests in the tourism resources and attracting tourists to visit the destination to maintain the persistent competitive advantage (Lu et al., 2017; Wu et al., 2017). Biljana et al. (2002) proposed to measure ecotourists' interests with natural areas, rainforests and native jungles, national parks, lakes and rivers, seaside, world heritage which were not being cultivated and interfered, nature learning, and photography of landscape and wild animals in order to understand visitors' interests in the uniqueness of the nature and to predict and confirm potential ecotourists. Perceived environmental involvement reveals close relations with interests, and interests are the content of perceived environmental involvement (Kapferer and Laurent, 1986; van Voorst and Hellman, 2015). Individual interests in certain affairs rely on individual characteristics. Interests and needs are major individual characteristics to affect the attention. An individual would search (expose) and examine (pay attention to) information related the requirement. Individual interests or involvement in certain brand or product reveal the attention to the brand or product related information. Referring to Oliver (1980) and Ajzen and Fishbein (1980), a consumer with higher interests or preference would appear higher involvement in the product or purchase behaviors. Meanwhile, referring to the psychological cognition process of belief (perception) $\rightarrow$ attitude, a consumer with higher interests or preference would show beneficial effects on the acceptance of tourism products. It is therefore inferred that H3: visitors' interests in tourism resources present 
direct and positive effects on perceived environmental involvement, and H6: visitors' interests in tourism resources reveal direct and positive effects on ecotourism support.

\section{Effects of perceived environmental involvement and support on behavioral intention}

Behavioral intention is often used for measuring future behavior. Oliver (1980) proposed the satisfaction decision cognition model that satisfactory evaluation and judgment resulted from purchase behaviors would affect behavioral intention. Zeithaml et al. (1996) argued that service quality would affect behavioral intention, was the indicator to judge successive purchase behaviors, and would result in financial results through behaviors.

As mentioned above, with high involvement, attitudes might be internalized that involvement would affect consumer behaviors. Past research discovered that involvement could effectively explain the changes in overseas tourism product purchase; it implied the correlations among involvement, attitude, and intention (Deery et al., 2017; Clarke and Mahadi, 2017). In this study, involvement is regarded as the dimension of belief, support as attitude, and behavioral intention as intention. According to Oliver's (1980) logic, visitors with higher ecotourism involvement would enhance the ecotourism support and behavioral intentions to ecotourism, and visitors enhance the ecotourism support would also enhance the behavioral intentions to ecotourism. Accordingly, the following hypotheses are established. H7: visitors' perceived environmental involvement appears direct and positive effects on ecotourism support. H8: Visitors' perceived environmental involvement shows direct and positive effects on behavioral intention. H9: Visitors' ecotourism support reveals direct and positive effects on behavioral intention.

\section{Methodology of research}

\section{Definition and measurement of variable}

The definition and measurement of variables are referred to relevant empirical research. In addition to good reliability and validity of original items, the current situations of ecotourism resources in Sichuan Province and the semantic meanings of items are taken into account. All items are measured with Likert's 7-point scale.

Referring to Flynn and Goldsmith (1993), innovation is defined as visitors' acceptance of novel tourism service. Referring to Kapferer and Laurent (1986), perceived risk is defined as visitors' perceived unfavorable results of new tourism product. Referring to Biljana et al. (2002) and the current situation of tourism resources in Sichuan Province, interest is defined as the attraction of tourism resources to visitors. According to Zaichkowsky (1994), perceived environmental involvement refers to visitors' overall perception of the correlation with purchased ecotourism products. Referring to Yoon et al. (2001), ecotourism support is defined as visitors' acceptance attitude towards ecotourism. Based on the definition of Zeithaml et al. (1996), behavioral intention reveals visitors' continuous and advantageous purchase behaviors to ecotourism in the future.

\section{Participants and procedures}

With judgmental sampling, visitors to Sichuan Province are regarded as the research samples in this study. Aiming at visitors returning from Sichuan Province as the object for the questionnaire survey, are preceded at Shuangliu Airport and the high speed rail station. Visitors to Sichuan Province concentrate on peak season that the survey is 
preceded during July - November, 2017, to enhance the representativeness by covering the peak season. The numbers of visitors in Sichuan Province is 600 million per year that is statistics data in 2017. A total of 1000 questionnaires were distributed, but 348 valid copies of questionnaire are acquired at last. The basic data of sampled visitors contain mostly female (53.2\%) and single (60.5\%), average age 24.8, students (43.9\%), monthly income about RMB 7000, and first time to Sichuan Province $(69.5 \%)$. SPSS is further utilized for the structural analysis of samples, exploratory factor analysis, and reliability analysis. According to the observation variables established in this study, the structural equation model (SEM) of causal relations among variable is constructed for testing the research hypotheses.

\section{Results of research}

Exploratory factor analysis aims to test the construct validity of dimensions in order to ensure the explanatory power and stability. Six items in innovation (Cronbach's $\alpha=0.88$ ), 5 items in perceived environmental involvement (Cronbach's $\alpha=0.86$ ), 5 items in support (Cronbach's $\alpha=0.83$ ), and 5 items in behavioral intention (Cronbach's $\alpha=0.91$ ) are separately extracted 1 dimension. Furthermore, 2 dimensions are extracted from 7 items in perceived risk, namely "psychological risk" (Cronbach's $\alpha=0.84$ ) and "real risk" (Cronbach's $\alpha=0.87), 3$ dimensions are extracted from 16 items in interest, namely "unique landscape resurces" (Cronbach's $\alpha=0.92$ ), "origin and integrity" (Cronbach's $\alpha=0.86$ ), and "folk culture" (Cronbach's $\alpha=0.81$ ), according to the factor loadings. The structural equation model (SEM) presents the standard factor loadings $\chi^{2}=227.45(\mathrm{df}=209), \chi^{2} / \mathrm{df}=1.09, \mathrm{p}=0.1345, \mathrm{GFI}=0.94, \mathrm{AGFI}=0.91, \mathrm{RMR}=0.04$, $\mathrm{RMSEA}=0.02, \mathrm{CFI}=0.97, \mathrm{NNFI}=0.98$, and NFI $=0.96$. All the measurements are shown in Table 1. Among 9 research hypotheses in this study, 3 paths of innovation $\rightarrow$ support, perceived risk $\rightarrow$ perceived environmental involvement, and perceived risk $\rightarrow$ support do not achieve the significant parameter estimate, while the rest of innovation $\rightarrow$ perceived environmental involvement, interest $\rightarrow$ perceived environmental involvement, interest $\rightarrow$ support, perceived environmental involvement $\rightarrow$ support, perceived environmental involvement $\rightarrow$ behavioral intention, and support $\rightarrow$ behavioral intention reach the significant parameter estimate of 0.01 . Overall speaking, 6 out of 9 research hypotheses are supported in this study.

\section{Discussion}

This study focuses on ecotourism, the emerging tourism, to discuss visitors' innovation tendency to tourism products, which is regarded as the content of personal traits. From the viewpoint of "resource-based theory" and combining existing natural resources in Sichuan Province, visitors' interests in tourism resources in Sichuan Province are discussed to construct the visitor behavioral intention integration model for further test. The structural equation model constructed in this study shows good fit. Figure 1 reveals that innovation, interest, and perceived risk are the antecedents of the causal model and would affect successive "perceived environmental involvement (integrated perception) $\rightarrow$ support (attitude) $\rightarrow$ behavioral intention". Apparently, the combination of "resource-based theory" with the psychological cognition model of "belief (perception) $\rightarrow$ attitude $\rightarrow$ intention" is verified in the research on ecotourism. 
Table 1. Measurement of variables

\begin{tabular}{|c|c|}
\hline Innovation & Cronbach's $\alpha$ \\
\hline $\begin{array}{l}\text { In my friends circle, I am always the first to visit a new attraction. } \\
\text { I am interested in trying out the new tour launched by the travel agency. } \\
\text { I love traveling more than others. } \\
\text { I know the latest tourist attractions before others. } \\
\text { I will consider visiting places where I have never heard before. } \\
\text { I know new sightseeing tours more than others. }\end{array}$ & 0.88 \\
\hline $\begin{array}{l}\text { Perceived risk } \\
\text { I am worried about whether the ecotourism itinerary is dangerous. } \\
\text { I will worry about choosing whether to participate in eco-tourism. } \\
\text { I am not sure if I will regret to participate in eco-tourism. } \\
\text { I will worry that the quality of eco-tourism is not as good as expected. } \\
\text { I will worry about the cost of eco-tourism. } \\
\text { I am not sure if the ecotourism trip has a special feature. }\end{array}$ & 0.86 \\
\hline $\begin{array}{l}\text { Interest } \\
\text { Sichuan has a variety of sightseeing resources } \\
\text { The scenery of Sichuan is incomparable in its area. } \\
\text { The scenery of Sichuan is unique } \\
\text { Sichuan has the equivalent of landscape in the world. } \\
\text { Sichuan has beautiful mountain views. } \\
\text { The geological landscape of Sichuan is amazing. } \\
\text { The natural scenery of Sichuan is refreshing. } \\
\text { The maintenance of the natural environment in Sichuan is quite perfect. } \\
\text { The preservation of the historic culture of Sichuan is quite complete. } \\
\text { The landscape of Sichuan maintains the original simplicity and tranquility. } \\
\text { The ancient architecture of Sichuan ancient temples and temples preserves the } \\
\text { traditional ancient style. } \\
\text { The natural environment of Sichuan will not be crowded and messy. } \\
\text { Sichuan is rich in native products. } \\
\text { Sichuan has a long history of historic buildings and cultural relics. }\end{array}$ & 0.83 \\
\hline $\begin{array}{c}\text { Perceived environmental involvement } \\
\text { Ecological sightseeing is important to me. } \\
\text { Eco-tourism is what makes me feel good. } \\
\text { My life is closely related to ecological sightseeing. } \\
\text { I am attracted to eco-tourism. } \\
\text { Ecotourism is valuable to me. }\end{array}$ & 0.86 \\
\hline $\begin{array}{c}\text { Ecotourism support } \\
\text { The development of ecological tourism in Sichuan is promising. } \\
\text { The development of ecological tourism in Sichuan is advantageous. } \\
\text { Sichuan develops ecological tourism is competitive. } \\
\text { Developing ecological tourism is beneficial to Sichuan. } \\
\text { Developing ecological tourism is worthwhile for Sichuan. }\end{array}$ & 0.83 \\
\hline $\begin{array}{l}\text { Behavior intention } \\
\text { Even if the cost is high, I will still consider participating in eco-tourism. } \\
\text { I am willing to participate in the ecological sightseeing of Sichuan in the future } \\
\text { In the future, I will give priority to participating in the ecological sightseeing of } \\
\text { Sichuan. } \\
\text { I will accept the recommendation of others to participate in the ecological sightseeing } \\
\text { of Sichuan. } \\
\text { I will recommend to my relatives and friends to participate in the ecological } \\
\text { sightseeing of Sichuan. }\end{array}$ & 0.91 \\
\hline
\end{tabular}

$\chi^{2}=227.45(\mathrm{df}=209), \chi^{2} / \mathrm{df}=1.09, \mathrm{p}=0.1345, \mathrm{GFI}=0.94$, AGFI $=0.91, \mathrm{RMR}=0.04, \mathrm{RMSEA}=$ $0.02, \mathrm{CFI}=0.97, \mathrm{NNFI}=0.98, \mathrm{NFI}=0.96$ 


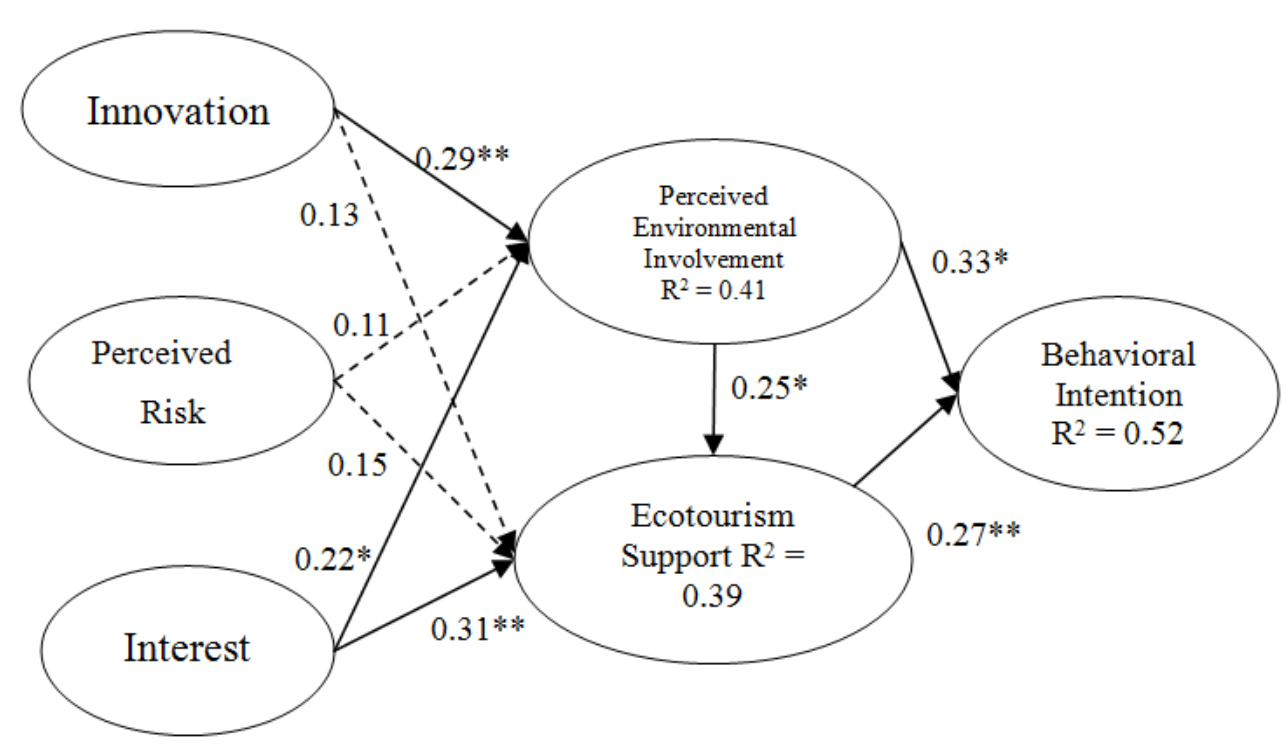

Figure 1. Empirical model

Moreover, the test of standardized parameter estimates in Figure 1 shows that 6 out of 9 causal paths constructed in this study are supported, where the effects of "perceived risk $\rightarrow$ perceived environmental involvement" and "perceived risk $\rightarrow$ support" are insignificant, revealing that visitors' perceived risk of ecotourism does not influence the intention to the future selection of ecotourism. It is inferred in this study that visitors still present perceived risk on emerging tourism, and the influence might be weaker and insignificant than innovation and interests. In regard to the development of ecotourism, the meaning of management is implied, while the effect of "innovation $\rightarrow$ support" is not significant, either, possibly because innovation is individual perception which could affect support (attitude) and successive behavioral intention through perceived environmental involvement. It is also proved that "innovation" and "interest" are the antecedents to affect visitors' future behavioral intention. It supports the ecotourism interest scale proposed by Biljana et al. (2002) to effectively explain visitors' participation in ecotourism activity as well as to predict and confirm the opinions of potential ecotourists by understanding visitors' interests in the uniqueness of nature and learning natural environment. Meanwhile, it also corresponds to the findings of $\mathrm{Xu}$ et al. (2017) and Hartini et al. (2017) that subjective curiosity plays extremely important role in the people's ecotourism motivation.

The analysis reveals (Table 2) total 5 influence paths of behavioral intention, with the total effect 0.288 , where 2 indirect paths driven by "innovation" (innovation $\rightarrow$ perceived environmental involvement $\rightarrow$ behavioral intention and innovation $\rightarrow$ perceived environmental involvement $\rightarrow$ support $\rightarrow$ behavioral intention) show the total effect $0.116(0.096+0.02)$ and 3 indirect paths driven by "interest" (interest $\rightarrow$ perceived environmental involvement $\rightarrow$ behavioral intention, interest $\rightarrow$ perceived environmental involvement $\rightarrow$ support $\rightarrow$ behavioral intention, and interest $\rightarrow$ support $\rightarrow$ behavioral intention) appear the total effect $0.171(0.073+0.015+0.083)$. In comparison with the effect, the antecedent drive of "interest" is stronger than it of "innovation". Apparently, "interest" is the key driving factor in visitors' future selection of ecotourism product. It is worth of relative units' emphases to develop marketing strategies. 
Table 2. Influence path and effect of behavioral intention

\begin{tabular}{|c|c|}
\hline Influence path & $\begin{array}{c}\text { Influence } \\
\text { effect }\end{array}$ \\
\hline Innovation $\rightarrow$ perceived environmental involvement $\rightarrow$ behavioral intention $(0.29 \times 0.33)$ & 0.096 \\
\hline Innovation $\rightarrow$ perceived environmental involvement $\rightarrow$ support $\rightarrow$ behavioral intention $(0.29 \times 0.25 \times 0.27)$ & 0.02 \\
\hline Interest $\rightarrow$ perceived environmental involvement $\rightarrow$ behavioral intention $(0.22 \times 0.33)$ & 0.073 \\
\hline Interest $\rightarrow$ perceived environmental involvement $\rightarrow$ support $\rightarrow$ behavioral intention $(0.22 \times 0.25 \times 0.27)$ & 0.015 \\
\hline Interest $\rightarrow$ perceived environmental involvement $\rightarrow$ behavioral intention $(0.31 \times 0.27)$ & 0.083 \\
\hline Total effect & 0.288 \\
\hline
\end{tabular}

\section{Implications}

In comparison with mass tourism, ecotourism is the tourism with innovative concept and has not been popularized. Understanding the behavioral intention of potential visitors to ecotourism is the core objective of a promotion unit. By summing up above analyses and discussions of behavioral intention, the management of marketing practice to promote ecotourism in Sichuan Province is proposed in this study as follows:

\section{(1) The conservation and maintenance strategies of core tourism resources}

"Interest" is the driving factor in visitors selecting emerging ecotourism products. Research findings show that the origin and integrity of ecology are the key components. Accordingly, the relevant promotion units are suggested to pay attention to core tourism resources, including the maintenance and conservation of natural environment and ancient culture. Traditional and original characters of landscape environment, ancient temples, and architecture and relics should be preserved. It should avoid from losing the original characteristics because of reconstruction and renewal in order to correspond to "nature" emphasized in ecotourism. In addition to the maintenance and conservation of natural and humanistic environment, the marketing and promotion strategies should stress on the natural and humanistic characteristics of "origin and integrity" in Sichuan Province to drive potential visitors' intention, by inducing the inner interests, to participate in ecotourism in Sichuan Province.

\section{(2) Innovation strategies for ecotourism products}

"Innovation" is also the driving factor in visitors' ecotourism product orientation. Research proves that new spots and new itineraries are the key components of innovation. Apparently, factors in potential visitors' future selection of ecotourism products reflect on individual inner characters. The relevant promotion units are therefore suggested to positively develop new ecotourism spots in Sichuan Province and integrate travel agents to promote ecotourism package tours so as to attract potential visitors of ecotourism by convenient tourism service.

\section{(3) Development potential and marketing and promotion strategies of ecotourism}

It is discovered in this study that ecotourism is the key component of support, revealing the evaluation of potential visitors to the development of ecotourism in Sichuan Province. Such information could encourage the confidence of relevant promotion units in promoting ecotourism to be the basis to continuously promote and develop ecotourism. What is more, word-of-mouth is the key component of behavioral 
intention, showing the importance of "word-of-mouth" and "behavioral loyalty" in the development of ecotourism in Sichuan Province. In this case, relevant promotion units should devote to the overall planning of ecotourism products and the management and promotion of the quality of ecotourism so as to attract potential visitors to participate in ecotourism and implement the promotion of ecotourism through the word-of-mouth and behavioral loyalty.

\section{REFERENCES}

[1] Ajzen, I., Fishbein, M. (1980): Understanding Attitudes and Predicting Social Behavior. Prentice-Hall, Englewood Cliffs, NJ.

[2] Biljana, J., Cornwell, T. B., Mather, D. (2002): Exploring the usefulness of an ecotourism interest scale. - Journal of Travel Research 40(3): 259-269.

[3] Chen, K. K. (2014): Assessing the effects of customer innovativeness, environmental value and ecological lifestyles on residential solar power systems install intention. Energy Policy 67: 951-961.

[4] Chiu, Y. T. H., Lee, W. I., Chen, T. H. (2014): Environmentally responsible behavior in ecotourism: antecedents and implications. - Tourism management 40: 321-329.

[5] Clarke, N., Mahadi, N. (2017): Differences between follower and dyadic measures of LMX as mediators of emotional intelligence and employee performance, well-being, and turnover intention. - European Journal of Work and Organizational Psychology 26(3): 373-384.

[6] Deery, S., Walsh, J., Zatzick, C. D., Hayes, A. F. (2017): Exploring the relationship between compressed work hours satisfaction and absenteeism in front-line service work.

- European Journal of Work and Organizational Psychology 26(1): 42-52.

[7] Engel, J. F., Blackwell, R. D., Miniard, P. W. (1995): Consumer Behavior (8th ed.). Dryden, Fort Worth, TX.

[8] Flynn, L. R., Goldsmith, R. E. (1993): Identifying innovators in consumer service markets. - The Service Industries Journal 13(3): 97-109.

[9] Frohlick, S., Johnston, L. (2011): Naturalizing bodies and places: tourism media campaigns and heterosexualities in Costa Rica and New Zealand. - Annals of Tourism Research 38(3): 1090-1109.

[10] Grant, R. M. (1991): The resource-based theory of competitive advantage: implications for strategy formulation. - California Management Review 33(3): 114-134.

[11] Hartini, N., Ariana, A. D., Dewi, T. K., Kurniawan, A. (2017): Improving urban environment through public commitment toward the implementation of clean and healthy living behaviors. - Psychology Research and Behavior Management 10: 79-84.

[12] Hetzer, N. D. (1965): Environment, tourism, culture. - Links 1(2): 1-3.

[13] Kapferer, J. N., Laurent, G. (1986): Consumer involvement profiles: a new practical approach to consumer involvement. - Journal of Advertising Research 25(6): 48-56.

[14] Laroche, M., Bergeron, J., Barbaro-Forleo, G. (2001): Targeting consumers who are willing to pay more for environmentally friendly products. - The Journal of Consumer Marketing 18(6): 503-520.

[15] Lee, C. K., Back, K. J. (2006): Examining structural relationships among perceived impact, benefit, and support for casino development based on 4 years longitudinal data. Tourism Management 27(3): 466-480.

[16] Lee, R. L. (2014): Travel, liquidity and order in Malaysian Modernity. - Asian Journal of Social Science 41(6): 580-599.

[17] Lu, D., Liu, Y., Lai, I., Yang, L. (2017): Awe: an important emotional experience in sustainable tourism. - Sustainability 9(12): 2189. doi.org/10.3390/su9122189. 
[18] Midgley, D., Dowling, G. R. (1978): Innovation: the concept and its measurement. Journal of Consumer Research 4: 229-242.

[19] Oliver, R. L. (1980): A cognitive model of the antecedents and consequences of satisfaction decisions. - Journal of Marketing Research 17(4): 460-469.

[20] Sahakian, M., Saloma, C., Ganguly, S. (2018): Exploring the role of taste in middle-class household practices. - Asian Journal of Social Science 46(3): 304-329.

[21] van Voorst, R., Hellman, J. (2015): One risk replaces another. - Asian Journal of Social Science 43(6): 786-810.

[22] Wu, T., Tsai, H. T., Tai, Y. N. (2016): Would corporate social responsibility affect consumers' attitudes towards brand and purchase behavior? Buyer-seller guanxi as the moderator. - Revista de Cercetare si Interventie Sociala 53: 272-287.

[23] Wu, T. J., Wu, Y. C. J., Tsai, H. T., Li, Y. B. (2017): Top management teams' characteristics and strategic decision-making: A mediation of risk perceptions and mental model. - Sustainability 9: 2265. DOI: 10.3390/su9122265.

[24] Xu, S., Mingzhu, L., Bu, N., Pan, S. (2017): Regulatory frameworks for ecotourism: An application of total relationship flow management theorems. - Tourism Management 61: 321-330.

[25] Yoon, Y., Gursoy, D., Chen, J. S. (2001): Validating a tourism development theory with structural equation modeling. - Tourism Management 22(4): 363-372.

[26] Zaichkowsky, J. L. (1994): The personal involvement inventory: reduction, revision, and application to advertising. - Journal of Advertising 23(4): 59-69.

[27] Zeithaml, V. A., Berry, L. L., Parasuraman, A. (1996): The behavioral consequences of service quality. - Journal of Marketing 60(2): 31-46. 